\title{
Crescimento e produtividade de cana-de-açúcar em função da disponibilidade hídrica dos Tabuleiros Costeiros de Alagoas
}

Magno Luiz de Abreu (1); Marcelo de Almeida Silva (2*); lêdo Teodoro (3); Lucas Almeida de Holanda (2); Givaldo Dantas Sampaio Neto $\left({ }^{4}\right)$

(') Instituto Federal de Educação, Ciência e Tecnologia de Mato Grosso (IFMT), Campus Parecis, 78360-000

Campo Novo dos Parecis (MT), Brasil.

(2) Universidade Estadual Paulista “Julio de Mesquita Filho" (UNESP), Faculdade de Ciências Agronômicas,

Departamento de Produção e Melhoramento Vegetal, Caixa Postal 237, 18603-970 Botucatu (SP), Brasil.

(3) Universidade Federal de Alagoas (UFAL), Centro de Ciências Agrárias, Departamento de Solos,

Engenharia e Economia Rural, 57100-000 Rio Largo (AL), Brasil.

(4) UNESP, Programa de Pós-Graduação em Irrigação e Drenagem, Caixa Postal 237, 18603-970 Botucatu (SP), Brasil.

${ }^{*}$ ) Autor correspondente: marcelosilva@fca.unesp.br

Recebido: 7/jun./2013; Aceito: 27/jun./2013

\section{Resumo}

O objetivo deste trabalho foi avaliar as interações entre variáveis meteorológicas e os componentes de produção e produtividade de seis variedades de cana-de-açúcar nos Tabuleiros Costeiros de Alagoas visando o manejo varietal adequado. O plantio da cana-de-açúcar foi realizado em setembro de 2005 na região de Rio Largo (AL) e as três colheitas foram feitas em novembro de 2006, novembro de 2007 e novembro de 2008. O delineamento estatístico utilizado foi o de blocos casualizados com o tratamento constituído pelas variedades RB863129, RB867515, RB92579, RB93509, RB931003 e RB951541, com quatro repetições. As variáveis de crescimento avaliadas foram número, comprimento e produtividade dos colmos, índice de área foliar e produtividade de açúcar. O balanço hídrico da cultura em média apresentou déficit hídrico de 869 mm nos meses de setembro a março e excesso hídrico de 837 mm nos meses de abril a agosto. A irregularidade das precipitações nos Tabuleiros Costeiros de Alagoas promove respostas diferenciais no desenvolvimento e na produtividade das variedades de cana-de-açúcar nos diferentes ciclos de cultivo. As variedades RB93509 e RB931003 são consideradas as melhores opções para o manejo varietal nessa região.

Palavras-chave: Saccharum spp., balanço hídrico, componentes da produção, ciclo de cultivo, variedades, produção.

\section{Growth and productivity of sugarcane varieties as affected by water availability in the Coastal Tablelands of the Alagoas State, Brazil}

\section{Abstract}

The aim of this study was to evaluate the interaction among meteorological variables and yield components of six sugarcane varieties and to establish appropriate varietal management at the Coastal Tablelands of the Alagoas State (Brazil). The sugarcane planting was carried out in September 2005, and three cane harvests were made in November 2006, 2007 and 2008. The experimental design was in randomized block with six treatments consisting of the varieties RB863129, RB867515, RB92579, RB93509, RB931003 and RB951541, with four replications. The growth variables evaluated were number and length of stalks, leaf area index, and productivity of stalks and sugar. On average, the crop water balance showed water deficit of $869 \mathrm{~mm}$ between September and March and excess of $837 \mathrm{~mm}$ from April to August. The irregularity of rainfall in the Coastal Tablelands promoted differential responses in the development and productivity of varieties of sugarcane. Varieties RB93509 and RB931003 are considered options for the varietal management in this region.

Key words: Saccharum spp., water balance, yield components, crop cycle, varieties, yield. 


\section{INTRODUÇÃO}

O Brasil é o maior produtor de cana-de-açúcar do mundo, colhendo 595,13 milhóes de toneladas por safra, em uma área de 8.520,5 mil hectares (ConAB, 2012). Desse total, a região Centro-sul produz $86,1 \%$ e a regiāo Norte-nordeste, $14,9 \%$. Vários fatores têm interferência na produçáo da cana-de-açúcar, com destaque para as interaçóes edafoclimáticas, manejo da cultura e variedade utilizada. No estado de Alagoas, o setor de maior impacto econômico é a agroindústria canavieira que, na safra 2008/2009, gerou 91 mil empregos diretos, sendo 70 mil rurais e 21 mil urbanos (SindaÇUCAR, 2011). A produção da cana-de-açúcar nos Tabuleiros Costeiros Alagoanos destaca-se pelo alto nível tecnológico, tanto no campo como na indústria. A área plantada é da ordem de 445,00 mil hectares e a produção na safra 2011/2012 foi de 23.622,6 milhóes de toneladas de cana moída (ConaB, 2012). A produtividade agrícola estimada no estado é de $53,90 \mathrm{t} \mathrm{ha}^{-1}$, considerada baixa quando comparada com a média de outras regióes produtoras como São Paulo, com 74,70 t ha ${ }^{-1}$, e Minas Gerais, com 72,43 t ha ${ }^{-1}$.

A variação climática anual na regiáo Nordeste do Brasil tem sido uma das principais causas de redução da produtividade agrícola. A disponibilidade de água é essencial para o crescimento e a produtividade da cana-de-açúcar, porque sua falta ou excesso pode influir diretamente na produção da cultura. Os níveis de produtividade agrícola na região canavieira do Nordeste ainda sáo baixos e isso pode estar associado ao déficit hídrico sofrido pela cultura no período de setembro a fevereiro, aliado ao uso de variedades não adaptadas às condiçôes do ambiente.

A deficiência hídrica é um dos mais importantes fatores que limitam a produção da cana-de-açúcar, e uma forma de contornar esse problema é cultivar variedades resistentes ou tolerantes à seca (Silva et al., 2008b) ou, ainda, aquelas classificadas como responsivas à melhoria do ambiente e que terăo alta produtividade sob disponibilidade hídrica. Ainda, de acordo com Silva (2008), uma variedade ideal é aquela que possua alta média de produção e baixo grau de flutuação em seu desempenho quando cultivada sob diversas condiçóes ambientais. Portanto, a recomendação de uma variedade depende da comprovação de sua constância como material genético em grande amplitude de condiçôes ambientais.

A necessidade hídrica da cana-de-açúcar altera-se com a fase vegetativa e a variedade utilizada. Essa cultura possui quatro fases de desenvolvimento: i) brotaçáo, ii) perfilhamento, iii) crescimento vegetativo, quando a cultura é bastante sensível à deficiência hídrica e às temperaturas fora de sua amplitude térmica ideal, isto é, entre $25^{\circ} \mathrm{C}$ e $33^{\circ} \mathrm{C}$, conforme Almeida et al. (2008), e iv) a maturaçáo, período em que ocorre o maior acúmulo de sacarose nos colmos (RAMEsH e Mahadevaswamy, 2000). O ideal é que na maturação aconteça um período de pouca disponibilidade hídrica. Em contrapartida, quando há restriçôes hídricas nas fases inicias de desenvolvimento, o crescimento dos colmos fica limitado, provocando também redução da produtividade da cultura. Essas fases de desenvolvimento e os aspectos morfofisiológicos da cana-de-açúcar devem ser estudados, uma vez que os conhecimentos sobre essa cultura são importantes para a adequação das variedades à regiáo considerada.

A análise de crescimento permite o estudo de diferentes variedades de uma cultura em diversos ambientes de produçáo (Oliveira et al., 2005). Novas variedades têm gerado ganhos de aproximadamente $30 \%$ na produtividade e qualidade da cana-de-açúcar (BARBosa et al., 2000), já que elas vêm com recomendação de áreas com maior ou menor adaptação edafoclimática.

Diante do exposto, o objetivo deste trabalho foi avaliar as interaçôes entre variáveis agrometeorológicas e os componentes da produtividade das variedades RB863129, RB867515, RB92579, RB93509, RB931003 e RB951541 de cana-de-açúcar nos Tabuleiros Costeiros de Alagoas, visando estabelecer manejo varietal adequado para alcançar melhor produtividade dessa cultura na regiáo.

\section{MATERIAL E MÉTODOS}

\section{Localização e caracterização da área experimental}

O experimento foi instalado próximo ao município de Rio Largo, AL (09²8'S; 3549'W e $127 \mathrm{~m}$ de altitude), em um solo classificado como Latossolo Amarelo Coeso argissólico, de textura média/argilosa (EMBRAPA, 2006). Características físico-hídricas do solo, com a umidade em base volumétrica: capacidade de campo de $0,244 \mathrm{~m}^{3} \mathrm{~m}^{-3}$, ponto de murcha permanente de $0,148 \mathrm{~m}^{3} \mathrm{~m}^{-3}$, densidade do solo de $1,23 \mathrm{mg} \mathrm{m}^{-3}$, porosidade total de $0,423 \mathrm{~m}^{3} \mathrm{~m}^{-3}$ e velocidade de infiltração básica de $52 \mathrm{~mm} \mathrm{~h}^{-1}$. O clima local é considerado quente e úmido e, segundo a classificação climática de Köppen, corresponde ao tipo As, caracterizado clima tropical, apresentando variaçóes térmicas entre $19,3^{\circ} \mathrm{C}$, em agosto, a $31,7^{\circ} \mathrm{C}$, em janeiro, com período seco entre os meses de setembro e fevereiro e período chuvoso concentrado no outono e inverno, precipitação anual de $1.818 \mathrm{~mm}$, com mínima de $41 \mathrm{~mm}$ em dezembro e máxima de $394 \mathrm{~mm}$ em julho.

\section{Instalação do experimento}

O plantio da cana-de-açúcar foi realizado em setembro de 2005. As parcelas foram constituídas de 11 linhas de 21 metros de comprimento, com espaçamento de $1,0 \mathrm{~m}$ entre linhas, totalizando área de $231 \mathrm{~m}^{2}$. O delineamento estatístico utilizado foi de blocos casualizados com seis tratamentos, constituídos pelas variedades RB863129, RB867515, RB92579, RB93509, RB931003 e RB951541, 
com quatro repetiçóes. A primeira colheita foi realizada em novembro de 2006, a segunda colheita, em novembro de 2007, e a terceira colheita, em novembro de 2008.

\section{Variáveis agrometeorológicas}

As variáveis agrometeorológicas foram armazenadas em uma estação automática de aquisição de dados Micrologger CR10X (Campbell Scientic, Logan, UT, EUA) instalada a $300 \mathrm{~m}$ do experimento. A precipitação pluvial foi obtida com um pluviômetro (TB3 Tipping Bucket Rain Gauge, Hydrological Services PTY. LTD., Sydney, Austrália). A temperatura e umidade relativa do ar foram mensuradas por um termo-higrômetro automático (HMP45C, Campbell Scientific, Logan, UT, EUA). A evapotranspiração da cultura foi calculada multiplicando-se a evapotranspiração de referência (ETo) pelo coeficiente de cultura (Kc) da FAO56. O valor de Kc na fase inicial tabelado da FAO56 $(0,40)$ foi corrigido pelo método gráfico da FAO (ALLEN et al., 1998), em funçáo do intervalo de tempo entre os eventos chuva e a magnitude da ETo.

O ciclo de desenvolvimento da cana-de-açúcar é dividido em quatro fases, porém nessa pesquisa, para melhorar o manejo da cultura (no sentido das técnicas de cultivo inerentes a cada fase de desenvolvimento), foi estabelecida a fenologia em três fases, conforme já utilizado por INMAN-BAMBER e SMITH (2005): (I) brotação até perfilhamento, caracterizada pelo crescimento lento e com duração de 120 a 200 dias após o plantio ou colheita (DAP ou DAC); (II) desenvolvimento da cultura ou grande crescimento, quando a altura das plantas aumenta rapidamente e a matéria seca acumulada chega a $75 \%$ do total, com início entre 120 a 200 DAP ou DAC e com duração de 130 a 200 dias; (III) maturação, caracterizada por crescimento lento e responsável por $11 \%$ da matéria seca, com duração de 100 dias, aproximadamente.

Os valores do Kc das fases de desenvolvimento da cultura e maturação foram os básicos de Doorenbos e Kassam (1979), corrigidos pela equação apresentada por Allen et al. (1998). Após a correçáo, os valores do Kc utilizados foram: de 0,7 a 1,3 na fase de desenvolvimento da cultura e de 0,7 na maturação. A ETo $\left(\mathrm{mm} \mathrm{dia}^{-1}\right)$ foi estimada pelo método de Penman-Monteith FAO56 (Allen et al., 1998).

O balanço hídrico decendial foi feito pelo método de Thornthwaite e Mather (1957), com a capacidade de água disponível (CAD) calculada pela equação:

$$
C A D(\mathrm{~mm})=\frac{(\bar{\theta} \mathrm{cc}-\bar{\theta} \mathrm{pmp})}{100} \times D \times P
$$

em que: CAD é a capacidade de água disponível, em milímetros; $\bar{\theta}$ cc é a umidade do solo quando na capacidade de campo, em porcentagem; $\bar{\theta}$ pmp é a umidade do solo quando no ponto de murcha permanente, em porcentagem;
D é a densidade volumétrica; e P é a profundidade efetiva do sistema radicular das plantas, em milímetros.

A profundidade efetiva do sistema radicular da cana-de-açúcar na região varia de $500 \mathrm{~mm}$ a $700 \mathrm{~mm}$ e, com base nos dados da umidade do solo na CC e PM, supracitadas, e com P igual a $60,0 \mathrm{~mm}$, a CAD calculada foi $58,2 \mathrm{~mm}$. Mas como $\mathrm{P}$ pode chegar até $700 \mathrm{~mm}$, o valor da CAD foi padronizado em 60,0 mm nos cálculos do balanço hídrico.

\section{Biometria e produtividade}

As avaliaçôes de índice de área foliar (IAF), comprimento de colmos (C) e número de perfilhos (NP) foram realizadas em três plantas marcadas nas três linhas centrais de cada parcela (área útil). As mensuraçôes foram iniciadas aos 60 dias após o plantio ou colheita, repetindo-se a cada 60 dias até o final do ciclo.

A área foliar (AF) foi determinada por meio da contagem do número de folhas verdes (folhas totalmente expandidas com mínimo de $20 \%$ de área verde) e por mediçôes de comprimento e largura das folhas +3 . Em seguida estimou-se a AF segundo a metodologia descrita por Hermann e Câmara (1999). Por meio dos valores da AF média de cada planta determinou-se o IAF de acordo com a equação:

IAF $\left(\mathrm{m}^{2} \mathrm{~m}^{-2}\right)=\left[(\right.$ AFP/Asolo $) \times \mathrm{n}^{\circ}$ de perfilhos por metro linear $]$

em que: AFP é a área foliar média de uma planta $\left(\mathrm{m}^{2}\right) \mathrm{e}$ Asolo, a área de terreno ocupada por uma planta $\left(\mathrm{m}^{2}\right)$.

As medidas de $\mathrm{C}$ foram feitas em 10 perfilhos industrializáveis - para tanto utilizou-se uma fita graduada em centímetros para medir a distância da base do colmo até o colarinho (dewlap) da folha +1 . Os perfilhos foram encaminhados para análise tecnológica. O NP por metro foi determinado de maneira direta, isto é, contando-se os perfilhos da parcela útil.

A avaliação da produtividade de colmos $(\mathrm{TCH})$ foi feita nas três linhas centrais e obtida com auxílio de um dinamômetro acoplado à garra de uma carregadeira de cana-de-açúcar. A TCH foi calculada por meio da massa de todos os colmos industrializáveis por parcela e da área ocupada por cada parcela $\left(\mathrm{t} \mathrm{ha}^{-1}\right)$. Para determinação da produtividade de açúcar (TPH), um feixe de dez colmos de cada parcela foi encaminhado ao laboratório de análises tecnológicas para obtenção da concentração de sacarose (pol\% cana). A TPH foi obtida por meio do produto entre a TCH e a pol\% cana dividido por 100 .

Os dados foram submetidos à análise de variância pelo teste $\mathrm{F}$ seguido da aplicação do teste de Tukey $(\mathrm{p}<0,05)$. Foi feita regressão nas variáveis de crescimento, com a curva que mais se ajustava a cada situaçáo. 


\section{RESULTADOS E DISCUSSÃO}

\section{Balanço hídrico}

Por meio do balanço hídrico do ciclo de cultivo da cana-planta foi observado déficit hídrico de $869 \mathrm{~mm}$, sendo $528 \mathrm{~mm}$ do terceiro decêndio de setembro de 2005 ao primeiro decêndio de abril de 2006, e de $341 \mathrm{~mm}$ no final do ciclo de cultivo, entre o segundo decêndio de agosto e o segundo decêndio de novembro de 2006. Por outro lado, do terceiro decêndio de abril ao primeiro decêndio de agosto de 2006 ocorreu excesso hídrico de $837 \mathrm{~mm}$ (Figura 1).

Em cana-soca, o déficit hídrico total foi de $651 \mathrm{~mm}$, sendo que $306,5 \mathrm{~mm}$ ocorreram do segundo decêndio de novembro de 2006 ao terceiro decêndio de abril de 2007 (na fase de estabelecimento da cultura) e $344,5 \mathrm{~mm}$, do primeiro decêndio de setembro de 2007 ao terceiro decêndio de novembro de 2007 (fase de maturação) (Figura 1). No período de maio a agosto de 2007 houve excesso de $411,1 \mathrm{~mm}$ (fase de crescimento vegetativo).

No terceiro ciclo de cultivo (ressoca), o balanço hídrico revelou o maior excesso hídrico $(1.036 \mathrm{~mm})$ entre os ciclos estudados (Figura 1). Observou-se ainda déficit hídrico de $699 \mathrm{~mm}$, dividido em dois períodos: $367 \mathrm{~mm}$ no início do desenvolvimento das plantas, entre o terceiro decêndio de novembro (2007) e o primeiro decêndio de março (2008), e $329 \mathrm{~mm}$ no período final do cultivo, do segundo decêndio de setembro ao terceiro decêndio de novembro de 2008.

Em três anos consecutivos de cultivo foi observado que a água excedente na estação da chuva foi em média de $736 \mathrm{~mm}$, isto é, equivalente à quantidade média deficiente na estação seca, $722 \mathrm{~mm}$, evidenciando a má distribuição das chuvas na regiáo dos Tabuleiros Costeiros de Alagoas. Na zona canavieira alagoana, a precipitação pluvial média é de $1.937 \mathrm{~mm}$, sendo que desse total $1.397,9 \mathrm{~mm}$ $(72,1 \%)$ ocorrem de abril a agosto e $539,6 \mathrm{~mm}(27,8 \%)$ precipitam-se entre setembro e março (SINDAÇUCAR, 2011), corroborando com nossos resultados. A necessidade hídrica da cana-de-açúcar nos Tabuleiros Costeiros de Alagoas está em torno de $4,9 \mathrm{~mm} \mathrm{dia}^{-1}$, totalizando $1.797 \mathrm{~mm}$ por ano (Teodoro et al., 2009), portanto, em tese, a quantidade de água precipitada seria suficiente para atender às necessidades hídricas da cultura. Assim, se a água excedente na estação chuvosa fosse armazenada nessa localidade seria suficiente para fazer irrigação plena da cultura durante a estação seca.

\section{Crescimento das plantas}

Tanto em cana-planta quanto na soca foi observado que o comprimento de colmos apresentou tendência a curva linear de crescimento em função do tempo em todas as variedades (Tabela 1). No entanto, em cana-ressoca somente o crescimento do comprimento dos colmos da variedade RB867515 apresentou tendência linear significativa, as demais variedades apresentaram tendência quadrática (Tabela 1).

Já para o número de perfilhos foi observado, em todos os ciclos e para todas as variedades, representação quadrática das curvas de tendência em função do tempo, com exceção da variedade RB92579, que não apresentou tendência de curva significativa na cana-soca (Tabela 2).

Em relação ao índice de área foliar em função do tempo, em cana-planta as variedades RB93509 e RB951541 náo apresentaram tendência de curva significativa, enquanto nas demais variedades a resposta foi representada por tendência linear. Desempenho diferente foi verificado na cana-soca: nela, as variedades RB92579, RB931003 e RB951541 não tiveram tendência de curva significativa, no entanto as variedades RB863129, RB867515 e RB93509 tiveram representação quadrática. E, no ciclo de ressoca, todas as variedades tiveram tendência de curva linear, com exceção da RB931003, que apresentou tendência quadrática (Tabela 3).

Poucas diferenças de comprimento dos colmos das variedades foram observadas nos três ciclos de cultivo. Entretanto, em cana-planta a variedade RB867515 foi a que apresentou maior crescimento final dos colmos e a RB951541, o menor. Confrontando-se esses dados com o balanço hídrico

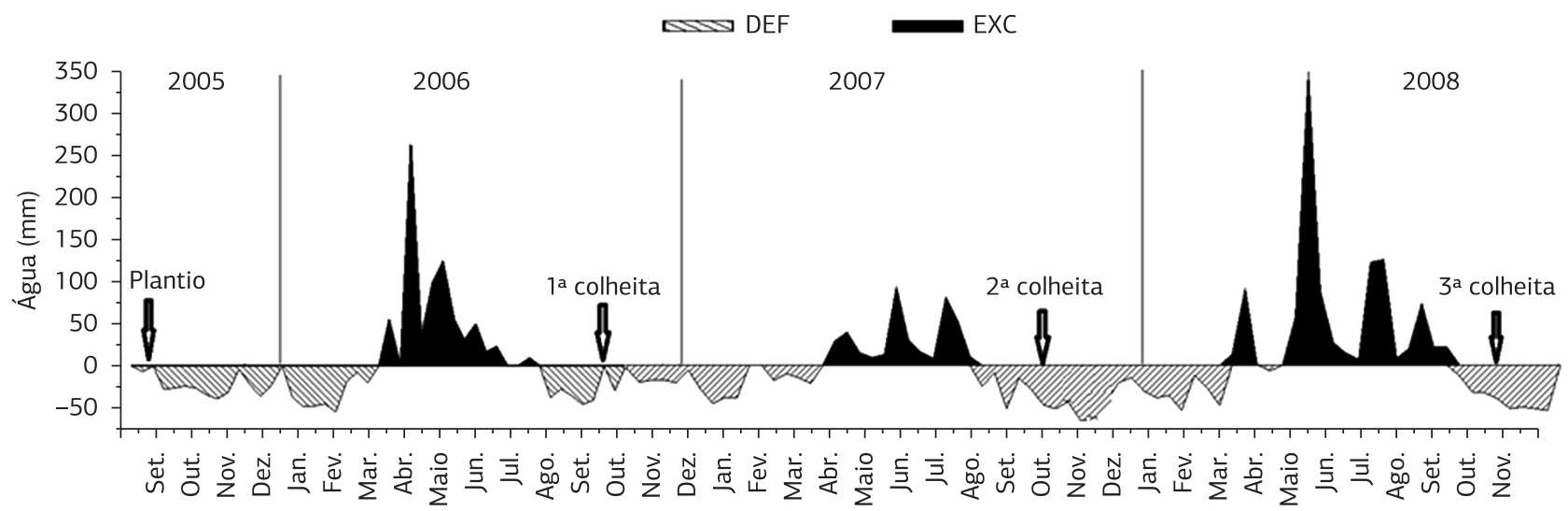

Figura 1. Balanço hídrico decendial da cultura, destaque para o déficit (DEF) e excesso (EXC) hídrico em cultivo de cana-de-açúcar (cana-planta, soca e ressoca) na região dos Tabuleiros Costeiros de Alagoas no período de setembro de 2005 a novembro de 2008. 
Tabela 1. Valor do quadrado médio (QM) da análise de regressão para comprimento dos colmos (C) de seis variedades de cana-de-açúcar durante os ciclos de cultivo de cana-planta, soca e ressoca na regiáo de Rio Largo, $\mathrm{AL}$

\begin{tabular}{|c|c|c|c|c|c|}
\hline Causa de variação & & & QM & & \\
\hline Variedades & Ciclo & Tendência da linha & C & Equação & $\mathbf{R}^{2}$ \\
\hline \multirow{3}{*}{ RB863129 } & Planta & Linear & $57858^{* *}$ & $y=(0,9583 x-41,358)$ & 0,97 \\
\hline & Soca & Linear & $49061^{* *}$ & $y=(0,8825 x-23,721)$ & 0,94 \\
\hline & Ressoca & Quadrática & $2738,3^{*}$ & $y=\left(-0,0024 x^{2}+1,6734 x-51,54\right)$ & 0,98 \\
\hline \multirow{3}{*}{ RB867515 } & Planta & Linear & $63942^{* *}$ & $y=(1,0074 x-50,997)$ & 0,96 \\
\hline & Soca & Linear & $30625^{* *}$ & $y=(0,6975 x+0,4533)$ & 0,88 \\
\hline & Ressoca & Linear & $36594^{* *}$ & $y=0,7621 x+34,9$ & 0,94 \\
\hline \multirow{3}{*}{ RB92579 } & Planta & Linear & $70665^{* *}$ & $y=(1,0591 x-64,801)$ & 0,97 \\
\hline & Soca & Linear & $55927^{* *}$ & $y=(0,9422 x-37,093)$ & 0,96 \\
\hline & Ressoca & Quadrática & $1334^{*}$ & $y=\left(-0,0017 x^{2}+1,4162 x-41,17\right)$ & 0,99 \\
\hline \multirow{3}{*}{ RB93509 } & Planta & Linear & $58433^{* *}$ & $y=(0,9631 x-55,789)$ & 0,98 \\
\hline & Soca & Linear & $49742^{* *}$ & $y=(0,8886 x-14,7)$ & 0,93 \\
\hline & Ressoca & Quadrática & $1520,7^{*}$ & $y=-0,0018 x^{2}+1,4373 x-31,48$ & 0,99 \\
\hline \multirow{3}{*}{ RB931003 } & Planta & Linear & $50666^{* *}$ & $y=(0,8968 x-53,811)$ & 0,96 \\
\hline & Soca & Linear & $54427^{* *}$ & $y=(0,9293 x-32,193)$ & 0,95 \\
\hline & Ressoca & Quadrática & $1328^{*}$ & $y=\left(-0,0029 x^{2}+2,0086 x-96,06\right)$ & 0,98 \\
\hline \multirow{3}{*}{ RB951541 } & Planta & Linear & $48817^{* *}$ & $y=(0,8803 x-41,629)$ & 0,95 \\
\hline & Soca & Linear & $50250^{* *}$ & $y=(0,8931 x-26,167)$ & 0,97 \\
\hline & Ressoca & Quadrática & $1783^{*}$ & $y=-0,0019 x^{2}+1,501 x-44,14$ & 0,98 \\
\hline
\end{tabular}

Tabela 2. Valores de quadrados médios (QM) da análise de regressão para o número de perfilhos (NP) de seis variedades de cana-de-açúcar durante os ciclos de cultivo de cana-planta, soca e ressoca na região de Rio Largo, AL

\begin{tabular}{|c|c|c|c|c|c|}
\hline \multicolumn{3}{|c|}{ Causa de variação } & \multicolumn{3}{|l|}{ QM } \\
\hline Variedades & Ciclo & Tendência da linha & NP & Equação & $\mathbf{R}^{2}$ \\
\hline \multirow{3}{*}{ RB863129 } & Planta & Quadrática & $40,74^{* *}$ & $y=\left(-0,0002 x^{2}+0,1136 x-0,69\right)$ & 0,97 \\
\hline & Soca & Quadrática & $28,23^{* *}$ & $y=\left(-0,0002 x^{2}+0,1309 x-2,29\right)$ & 0,98 \\
\hline & Ressoca & Quadrática & $35,88^{* *}$ & $y=\left(-0,0003 x^{2}+0,1414 x-2,93\right)$ & 0,98 \\
\hline \multirow{3}{*}{ RB867515 } & Planta & Quadrática & $40,74^{*}$ & $y=\left(-0,0003 x^{2}+0,1386 x-0,67\right)$ & 0,96 \\
\hline & Soca & Quadrática & $53,92^{*}$ & $y=\left(-0,0003 x^{2}+0,1609 x-2,59\right)$ & 0,97 \\
\hline & Ressoca & Quadrática & $54,89^{* *}$ & $y=\left(-0,0003 x^{2}+0,1607 x-2,65\right)$ & 0,98 \\
\hline \multirow{3}{*}{ RB92579 } & Planta & Quadrática & $22,86^{* *}$ & $y=\left(-0,0001 x^{2}+0,0784 x+2,95\right)$ & 0,96 \\
\hline & Soca & & $25,85^{\text {ns }}$ & & \\
\hline & Ressoca & Quadrática & $25,74^{* *}$ & $y=\left(-0,0002 x^{2}+0,1269 x-2,45\right)$ & 0,99 \\
\hline \multirow{3}{*}{ RB93509 } & Planta & Quadrática & $31,02^{* *}$ & $y=\left(-0,0002 x^{2}+0,1111 x+0,09\right)$ & 0,97 \\
\hline & Soca & Quadrática & $33,06^{* *}$ & $y=\left(-0,0003 x^{2}+0,1308 x-0,87\right)$ & 0,98 \\
\hline & Ressoca & Quadrática & $45,91^{* *}$ & $y=\left(-0,0003 x^{2}+0,1522 x-2,65\right)$ & 0,99 \\
\hline \multirow{3}{*}{ RB931003 } & Planta & Quadrática & $11,12^{*}$ & $y=-0,0002 x^{2}+0,1139 x+1,51$ & 0,87 \\
\hline & Soca & Quadrática & $33,44^{*}$ & $y=\left(-0,0003 x^{2}+0,1277 x+0,02\right)$ & 0,91 \\
\hline & Ressoca & Quadrática & $32,68^{*}$ & $y=\left(-0,0003 x^{2}+0,128 x-0,46\right)$ & 0,91 \\
\hline \multirow{3}{*}{ RB951541 } & Planta & Quadrática & $25,80^{*}$ & $y=\left(-0,0003 x^{2}+0,139 x-1,7\right)$ & 0,97 \\
\hline & Soca & Quadrática & $45,64^{* *}$ & $y=\left(-0,0003 x^{2}+0,1494 x-2,65\right)$ & 0,97 \\
\hline & Ressoca & Quadrática & $55,53 * *$ & $y=\left(-0,0003 x^{2}+0,1631 x-3,87\right)$ & 0,99 \\
\hline
\end{tabular}

da cultura (Figura 1), verifica-se que na cana-planta houve deficiência hídrica de $579 \mathrm{~mm}$ entre o primeiro decêndio de setembro de 2005 até o terceiro decêndio de abril de 2006. Essa deficiência prejudicou o desenvolvimento inicial da cultura, resultando em comprimento médio dos colmos de $171 \mathrm{~cm}$. Entre o primeiro decêndio de maio e o último decêndio de agosto, a cultura passou por excesso hídrico de $696 \mathrm{~mm}$, o que estimulou o crescimento das plantas e levou o comprimento médio final de colmos a atingir $359 \mathrm{~cm}$. No final do ciclo de produçáo (do primeiro decêndio de setembro até o último decêndio de novembro de 2006), a cultura foi submetida a déficit hídrico $(215 \mathrm{~mm})$, o qual foi benéfico em virtude de favorecer a maturação das plantas.

Quando observado o crescimento dos colmos em cana-soca (Tabela 1), verifica-se que a variedade RB931003 foi a que teve maior comprimento dos colmos no final do ciclo e a 
Tabela 3. Valores de quadrados médios $(\mathrm{QM})$ da análise de regressão para o índice de área foliar (IAF) de seis variedades de cana-de-açúcar durante os ciclos de cultivo de cana-planta, soca e ressoca na regiáo de Rio Largo, $\mathrm{AL}$

\begin{tabular}{|c|c|c|c|c|c|}
\hline \multicolumn{3}{|c|}{ Causa de variação } & \multicolumn{3}{|l|}{ QM } \\
\hline Variedades & Ciclo & Tendência da linha & IAF & Equação & $\mathbf{R}^{2}$ \\
\hline \multirow{3}{*}{ RB863129 } & Planta & Linear & $57,86^{* *}$ & $y=(0,0066 x+1,1427)$ & 0,61 \\
\hline & Soca & Quadrática & $3,01^{* *}$ & $y=\left(-8 E-05 x^{2}+0,0317 x+0,99\right)$ & 0,95 \\
\hline & Ressoca & Linear & $11,04^{*}$ & $y=(0,0132 x+1,2533)$ & 0,68 \\
\hline \multirow{3}{*}{ RB867515 } & Planta & Linear & $3,43^{*}$ & $y=\left(-2 E-05 x^{2}+0,0167 x+0,39\right)$ & 0,73 \\
\hline & Soca & Quadrática & $1,04^{*}$ & $y=\left(3 E-05 x^{2}-0,0166 x+4,28\right)$ & 0,50 \\
\hline & Ressoca & Linear & $16,32^{*}$ & $y=(0,0161 x+1,4867)$ & 0,67 \\
\hline \multirow{3}{*}{ RB92579 } & Planta & Linear & $15,29^{* *}$ & $y=(0,0156 x+0,0447)$ & 0,76 \\
\hline & Soca & & $0,10^{\text {ns }}$ & & \\
\hline & Ressoca & Linear & $19,03^{*}$ & $y=(0,0132 x+1,2533)$ & 0,68 \\
\hline \multirow{3}{*}{ RB93509 } & Planta & & $2,56^{\mathrm{ns}}$ & & \\
\hline & Soca & Quadrática & $3,24^{*}$ & $y=\left(-8 E-05 x^{2}+0,0304 x+1,59\right)$ & 0,83 \\
\hline & Ressoca & Linear & $23,32^{*}$ & $y=(0,0192 x+0,9267)$ & 0,71 \\
\hline \multirow{3}{*}{ RB931003 } & Planta & Linear & $6,10^{*}$ & $y=(-6 E-06 x 2+0,0125 x-0,022)$ & 0,95 \\
\hline & Soca & & $0,08^{\text {ns }}$ & & \\
\hline & Ressoca & Quadrática & $3,44^{*}$ & $y=\left(-9 E-05 x^{2}+0,0485 x-1,08\right)$ & 0,98 \\
\hline \multirow{3}{*}{ RB951541 } & Planta & & $1,54^{\mathrm{ns}}$ & & \\
\hline & Soca & & $0,08^{\mathrm{ns}}$ & & \\
\hline & Ressoca & Linear & $8,85^{*}$ & $y=(0,0119 x+1,2933)$ & 0,52 \\
\hline
\end{tabular}

RB863129, o menor. No entanto, no período de maior disponibilidade hídrica, maio a agosto de 2007, observou-se melhor resposta na variedade RB93509 e, em consequência, maior comprimento dos colmos. Entretanto, essa última variedade não sustentou esse resultado até o final do ciclo, quando passou pelo segundo período de deficiência hídrica.

No terceiro ciclo de cultivo, cana-ressoca, foi observado na variedade RB867515 maior comprimento dos colmos e, na RB863129, o menor (Tabela 1). Vale ressaltar que a RB867515 teve menor crescimento em cana-soca. Na ressoca houve o período de maior precipitação, resultando no maior excesso hídrico $(1.036 \mathrm{~mm})$ dos três ciclos. Observa-se ainda que do déficit hídrico de $699 \mathrm{~mm}$, apenas $367 \mathrm{~mm}$ ocorreram no início do desenvolvimento das plantas, entre o terceiro decêndio de novembro de 2007 e o primeiro decêndio de março de 2008, enquanto $329 \mathrm{~mm}$ ocorreram no período final do cultivo (do segundo decêndio de setembro ao terceiro decêndio de novembro de 2008).

Entre os fatores de maior importância para atingir alta produtividade na cana-de-açúcar está o conhecimento dos padrôes de crescimento de cada variedade, o que permite manejar a cultura para que as fases de máximo desenvolvimento coincidam com os períodos de maior disponibilidade hídrica, sem negligenciar, no entanto, a importância da umidade do solo nas fases de brotação, emergência e perfilhamento (AlmEIDA et al., 2008). Portanto, o conhecimento das curvas de crescimento durante o ciclo de produção das variedades de cana-de-açúcar é importante para ajustá-las aos períodos de maior disponibilidade hídrica ou para determinar quantidades de aplicação de água via irrigação em períodos plenos ou de salvação da cultura.
A variável número de perfilhos teve tendência similar de crescimento em cana-planta, soca e ressoca para as variedades estudadas (Tabela 2), no entanto, na RB867515 foi verificada maior quantidade de perfilhos nos três ciclos da cultura aos 240 dias, coincidindo com o período de maior disponibilidade de água (Figura 1), seguida de uma acentuada reduçáo no perfilhamento, atribuída ao período de déficit hídrico no solo, além do aumento da competição intraespecífica por água, luz, nutrientes e espaço, levando à morte os perfilhos mais jovens, fracos e mal posicionados (Silva et al., 2008a). Ao final do período de crescimento dos três ciclos, a variedade RB863129 apresentou, em média, o maior número de perfilhos, enquanto a RB951541, o menor. Contudo, verificou-se na variedade RB863129 maior número de perfilhos na cana-planta e na soca, ou seja, ciclos em que houve déficit hídrico acentuado, evidenciando-se sua capacidade de tolerância, sendo ela, portanto, uma opçáo de manejo varietal para a regiáo dos Tabuleiros Costeiros de Alagoas.

Em relação ao índice de área foliar (IAF), constatou-se influência do regime hídrico do ciclo de cultivo: na cana-soca, que apresentou o maior déficit hídrico nesta pesquisa, foi verificado o menor IAF para todas as variedades. Dentro de cada ciclo, os maiores valores de IAF foram observados durante os períodos de maior precipitação, entre maio e agosto, devido à condiçáo favorável ao crescimento vegetativo, depois esses valores decresceram devido à senescência das folhas, em funçáo da deficiência hídrica e da maturação da cultura (Tabela 3 e Figura 1).

Em cana-planta, o maior IAF foi verificado na variedade RB92579 e o menor, na RB867515 (Tabela 3). No ciclo 
de cana-soca constatou-se o maior IAF na variedade RB93509 e novamente na variedade RB867515, o menor, ressaltando-se que nessa variedade foi observado também o menor comprimento dos colmos nesse ciclo, o que revela a importância do desenvolvimento da área foliar para o estabelecimento da cultura e o fechamento do dossel, assim como para a maximizaçáo da interceptação da radiação fotossinteticamente ativa (Sinclair et al., 2004). No ciclo de cultivo da ressoca, o de menor déficit hídrico, a variedade RB93509 foi a que apresentou o maior IAF e a variedade RB951541, o menor, no entanto a RB867515, que teve o menor IAF nos dois ciclos anteriores, apresentou o segundo maior IAF e o maior comprimento dos colmos (Tabela 1).

Nos Tabuleiros Costeiros Alagoanos, Almeida et al. (2008) observaram que a variedade RB92579 alcançou valores de IAF superiores a 3 aos 100 dias após o plantio, o que contribuiu para a melhor eficiência no uso da água e para o maior acúmulo de matéria seca e, ainda, que esta variedade sempre apresentou IAF elevado e resposta rápida à disponibilidade hídrica. Essa regiáo é sujeita a períodos de déficit hídrico acentuado, com grande perda de água por evapotranspiração. Em relação ao ciclo fenológico da cana-de-açúcar, esses períodos coincidem com maior perfilhamento, levando à competição intrínseca por água. No entanto, no período de grande crescimento da cultura há disponibilidade hídrica, assim maiores produtividades podem ser alcançadas no manejo de variedades com respostas rápidas em IAF e comprimento dos colmos nesses períodos.

\section{Produtividade agrícola}

Durante o ciclo da cana-planta não houve diferença significativa para a produtividade de colmos $(\mathrm{TCH})$ entre as variedades, porém a RB92579 destacou-se como a mais produtiva em valores absolutos (Figura 2a). A TCH nesse ciclo variou de $102 \mathrm{t}$ a $76 \mathrm{t} \mathrm{ha}^{-1}$.

$\mathrm{Na}$ cana-soca, as TCHs foram menores, média de $75 \mathrm{tha}^{-1}$ : a variedade RB92509 foi a mais produtiva $\left(95,8 \mathrm{t} \mathrm{ha}^{-1}\right)$, acompanhada das variedades RB931003, RB867515 e RB92579, enquanto a menor TCH foi creditada para RB863129 (65,8 $\mathrm{t} \mathrm{ha}^{-1}$ ) (Figura 2a). Durante o ciclo de cana-soca houve maior déficit hídrico, ou seja, de $544 \mathrm{~mm}$ em 210 dias, o que refletiu em menor produtividade média. Dessa deficiência hídrica, $181 \mathrm{~mm}$ ocorreram em até 80 dias

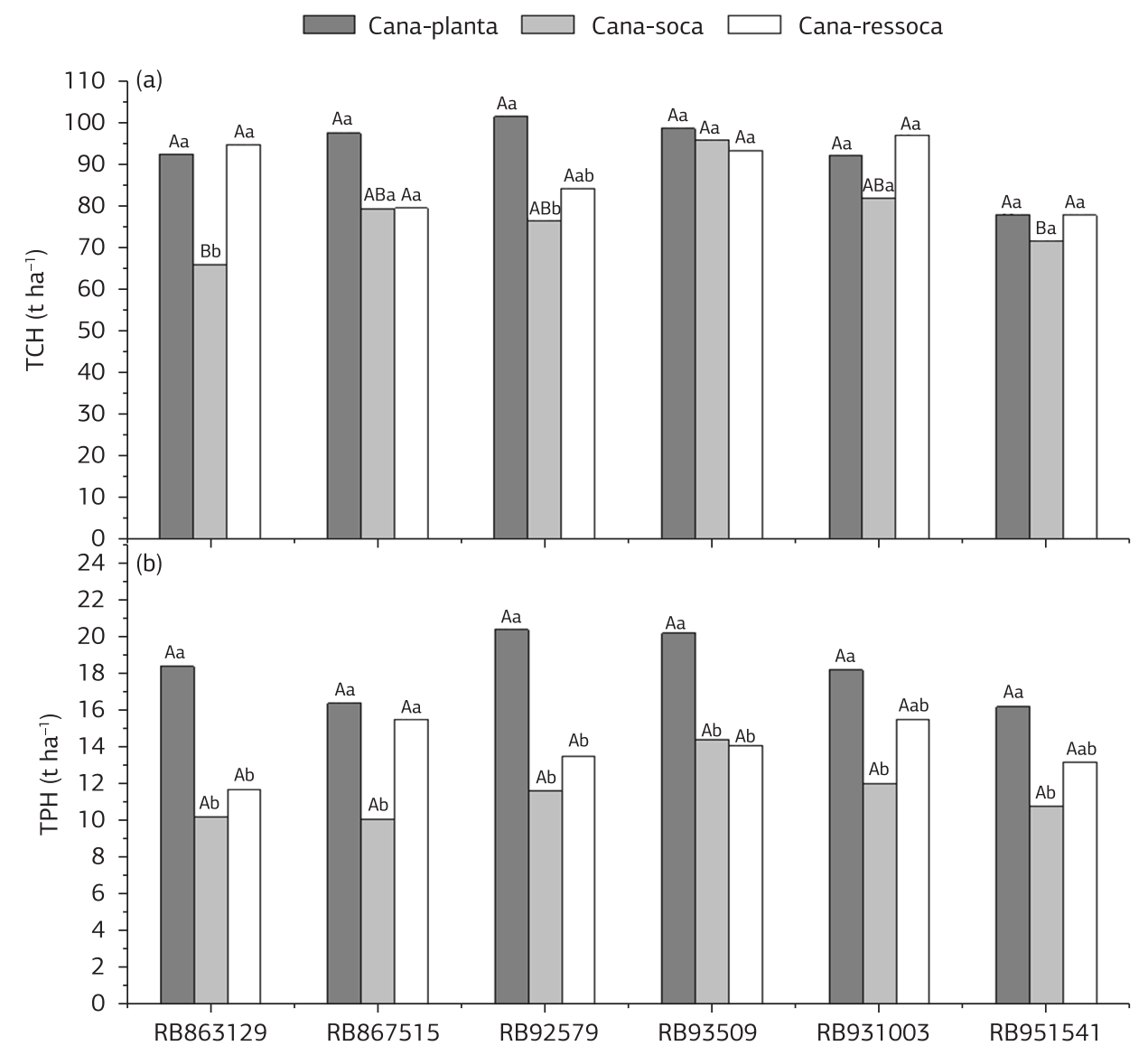

Figura 2. Produtividade de colmos (TCH) (a) e de açúcar (TPH) (b) de seis variedades de cana-de-açúcar nos ciclos da cana-planta (2005-2006), cana-soca (2006-2007) e cana-ressoca (2007-2008) na região de Rio Largo, AL; médias entre as variedades e dentro do mesmo ciclo seguidas por mesma letra maiúscula e médias dentro da mesma variedade e entre ciclos seguidas por mesma letra minúscula não diferem entre si pelo teste de Tukey a 5\% de significância. 
antes da colheita do primeiro cultivo, o que prejudicou a brotaçáo da soqueira, situaçáo agravada ainda mais pelo restante do estresse $(363 \mathrm{~mm})$ ter ocorrido nos 130 dias iniciais do desenvolvimento da cultura (Figura 1).

No terceiro ciclo de cultivo, apesar de não ter havido diferença significativa, a TCH média foi de $88 \mathrm{t} \mathrm{ha}^{-1}$, isto é, bem próxima da cana-planta $\left(89 \mathrm{t} \mathrm{ha}^{-1}\right)$. Algumas variedades destacaram-se por apresentar TCHs médias maiores na cana-ressoca do que na cana-planta, tais como as variedades RB931003, RB93509 e RB867515, que produziram na cana-planta 92 t, 98 t e 92 t ha $^{-1}$ e, na ressoca, 107 t, 100 t e $99 \mathrm{t} \mathrm{ha}^{-1}$, respectivamente. Nesse ciclo, a variedade menos produtiva foi a RB951541, com 77,6 $\mathrm{t} \mathrm{ha}^{-1}$. As maiores TCHs no terceiro cultivo podem ser atribuídas ao menor déficit hídrico $(367 \mathrm{~mm})$ no período de brotação e desenvolvimento inicial (Figura 1), o que levou ao melhor perfilhamento das plantas (Tabela 2).

Nos três ciclos de cultivo verificou-se que a variedade RB93509 foi a menos afetada pelos regimes hídricos dos anos agrícolas, não apresentando diferença significativa entre as TCHs (Figura 2a) e apresentando, ainda, a maior média nos três ciclos, 95,9 t ha ${ }^{-1}$, seguida pela RB931003, com média de 91,2 $\mathrm{t} \mathrm{ha}^{-1}$ (Figura 3), o que demonstra sua rusticidade e estabilidade sob variaçôes climáticas, sendo esta variedade indicada para cultivo na regiāo. Por outro lado, a variedade RB863129, apesar de responsiva aos anos com maior pluviosidade durante o período de grande crescimento, foi a que menos produziu em ano de forte restrição hídrica, e a variedade RB951541 foi a que apresentou menor média de TCH nos três ciclos, o que indica não serem essas variedades recomendadas para cultivo nos Tabuleiros Costeiros Alagoanos.
Quanto à produtividade de açúcar (TPH), não foram observadas diferenças entre as variedades em nenhum dos três ciclos avaliados (Figura 2b). Entretanto, entre ciclos houve respostas diferenciadas para as variedades. $\mathrm{Na}$ cana-planta foram observados os maiores valores de TPH e na cana-soca, os menores, certamente influenciados pela deficiência hídrica observada no segundo ciclo, que levou à redução da TCH (Figura 2a), um dos componentes na obtenção da TPH. Na cana-ressoca foram observadas as menores TPHs nas variedades RB863129, RB92579 e RB93509, as quais não se diferenciaram da cana-soca, porém a RB867515 respondeu positivamente às condiçôes climáticas no terceiro ciclo e teve TPH semelhante à do primeiro ciclo (Figura 2b). Na média dos três ciclos, a variedade RB93509 destacou-se por apresentar o maior valor, 16,2 $\mathrm{t} \mathrm{ha}^{-1}$ (Figura 3), seguida pelas variedades RB931003, RB92579 e RB867515, confirmando-se assim sua aptidão para a região.

Almeida et al. (2008) também encontraram respostas diferenciadas entre quatro variedades de cana-de-açúcar cultivadas em dois ciclos (cana-planta e cana-soca) na região dos Tabuleiros Costeiros Alagoanos: a variedade RB92579 foi indicada como melhor opção de cultivo para aquelas condições. Oliveira et al. (2010), estudando o comportamento de variedades de cana-de-açúcar apenas no primeiro ciclo de cultivo na regiáo de Carpina, $\mathrm{PE}$, registraram que a RB92579, apesar de não apresentar altura e diâmetro superiores aos das demais variedades, foi a mais produtiva, evidenciando que outras características morfológicas, como o perfilhamento e o índice de área foliar, podem ser mais decisivas na produçáo final de matéria seca. GAVA et al. (2011), estudando três variedades de cana-de-açúcar também em cana-planta na regiáo de Jaú, SP, observaram que a variedade

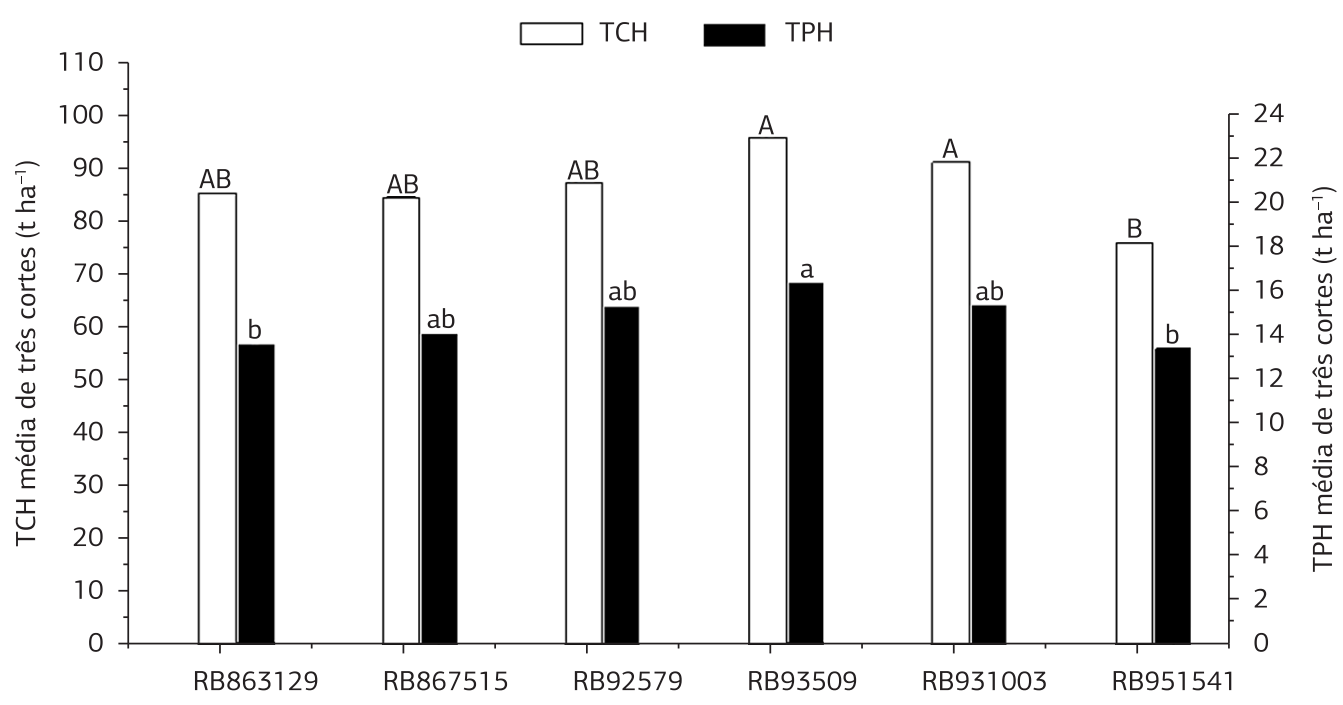

Figura 3. Produtividade média de colmos (TCH) e de açúcar (TPH) nos três ciclos de cultivo (2005-2006, 2006-2007 e 2007-2008) de seis variedades de cana-de-açúcar na regiáo de Rio Largo, AL; médias entre as variedades seguidas por mesma letra maiúscula para TCH e médias dentro da mesma variedade seguidas por mesma letra minúscula para TPH não diferem entre si pelo teste de Tukey a 5\% de significância. 
RB867515 foi a mais produtiva tanto sob disponibilidade quanto sob restrição hídrica.

Neste estudo, a variedade RB92579 destacou-se na cana-planta com o maior IAF e o maior TCH em valores absolutos. A variedade RB867515 também despontou entre as mais produtivas na cana-planta e, apesar de afetada pela deficiência hídrica na cana-soca, foi responsiva para TPH nas melhores condiçóes hídricas do ciclo de cana-ressoca. Entretanto, as variedades RB93509 e RB931003 surgiram como as melhores opções a considerar no manejo varietal na região dos Tabuleiros Costeiros de Alagoas devido à estabilidade da produção de colmos e de açúcar ao longo dos diferentes ciclos de cultivo.

\section{CONCLUSÃO}

A irregularidade das precipitaçôes nos Tabuleiros Costeiros de Alagoas promoveu respostas diferenciais no desenvolvimento e na produtividade das variedades de cana-de-açúcar nos diferentes ciclos de cultivo. As variedades RB93509 e RB931003 têm melhor desempenho nas diferentes condições hídricas de cultivo e são consideradas opçóes para o manejo varietal nessa região.

\section{REFERÊNCIAS}

ALLEN, R.G.; PEREIRA, L.S.; RAES, D.; SMITH, M. Crop evapotranspiration: Guidelines for computing crop water requirements. Rome: FAO, 1998. 300p. (FAO. Irrigation and Drainage Paper, n.56).

ALMEIDA, A.C.S.; SOUZA, J.L.; TEODORO, I.; BARBOSA, G.V.S.; MOURA FILHO, G.; FERREIRA JÚNIOR, R.A. Desenvolvimento vegetativo e produção de variedades de cana-de-açúcar em relação à disponibilidade hídrica e unidades térmicas. Ciência e Agrotecnologia, v.32, p.1441-1448, 2008. http://dx.doi.org/10.1590/S141370542008000500013

BARBOSA, G.V.S.; SOUZA, A.J.R.; ROCHA, A.M.C.; RIBEIRO, C.A.G.; FERREIRA, J.L.C.; SOARES, L.; CRUZ, M.M.; SILVA, W.C.M. Novas variedades RB de cana-de-açúcar para Alagoas. Maceió: UFAL; Programa de Melhoramento Genético de Cana-deAçúcar, 2000. 16p. (Boletim Técnico Programa de Melhoramento Genético de Cana-de-Açúcar).

COMPANHIA NACIONAL DE ABASTECIMENTO - CONAB. Safra 2011/2012. Terceiro Levantamento (novembro/2012). Dispoível em: <http://www.conab.gov.br>. Acesso em: nov. 2012.

DOORENBOS, J.; KASSAM, A.H. Yields response to water. Rome: FAO, 1979. 306p. (FAO: Irrigation and Drainage Paper, n.33).

EMPRESA BRASILEIRA DE PESQUISA AGROPECUÁRIA - EMBRAPA. Centro Nacional de Pesquisa de Solos. Sistema brasileiro de classificação de solos. Rio de Janeiro, 2006. 306p.

GAVA, G.J.G.; SILVA, M.A.; SILVA, R.C.; JERÔNIMO, E.M.; CRUZ, J.C.S.; KÖLLN, O.T. Produtividade de três cultivares de cana-de-açúcar sob manejos de sequeiro e irrigado por gotejamento. Revista Brasileira de Engenharia Agrícola e Ambiental, v.15, p.250255, 2011. http://dx.doi.org/10.1590/S1415-43662011000300005

HERMANN, E.R.; CÂMARA, G.M.S. Um método simples para estimar a área foliar de cana-de-açúcar. Revista da STAB, v.17, p.32-35, 1999.

INMAN-BAMBER, N.G.; SMITH, D.M. Water relations in sugarcane and response to water deficits. Field Crops Research, v.92, p.185202, 2005. http://dx.doi.org/10.1016/j.fcr.2005.01.023

OLIVEIRA, R.A.; DAROS, E.; ZAMBON, J.L.C.; WEBER, H.; IDO, O.T.; ZUFELLATO-RIBAS, K.C.; KOEHLER, H.S.; SILVA, D.K.T. Crescimento e desenvolvimento de três cultivares de cana-deaçúcar, em cana-planta, no estado do Paraná: Taxas de crescimento. Scientia Agraria, v.6, p.85-89, 2005.

OLIVEIRA, E.C.A.; OLIVEIRA, R.I.; ANDRADE, B.M.T.; FREIRE, F.J.; LIRA JÚNIOR, M.A.; MACHADO, P.R. Crescimento e acúmulo de matéria seca em variedades de cana-de-açúcar cultivadas sob irrigação plena. Revista Brasileira de Engenharia Agrícola e Ambiental, v.14, p.951-960, 2010. http://dx.doi.org/10.1590/S141543662010000900007

RAMESH, P.; MAHADEVASWAMY, M. Effect of formative phase drought on different classes of shoots, shoot mortality, cane attributes, yield and quality of four sugarcane cultivars. Journal of Agronomy \& Crop Science, v.185, p.249-258, 2000. http://dx.doi. org/10.1046/j.1439-037x.2000.00399.x

SILVA, M.A. Interação genótipo x ambiente e estabilidade fenotípica de cana-de-açúcar em ciclo de cana de ano. Bragantia, v.67, p.109117, 2008. http://dx.doi.org/10.1590/S0006-87052008000100013

SILVA, M.A.; JERONIMO, E.M.; LÚCIO, A.D. Perfilhamento e produtividade de cana-de-açúcar com diferentes alturas de corte e épocas de colheita. Pesquisa Agropecuária Brasileira, v.43, p.979986, 2008a. http://dx.doi.org/10.1590/S0100-204X2008000800005

SILVA, M.A.; SOARES, R.A.B.; LANDELL, M.G.A.; CAMPANA, M.P. Agronomic performance os sugarcane families in response to water stress. Bragantia, v.67, p.655-661, 2008b. http://dx.doi.org/10.1590/ S0006-87052008000300014

SINDICATO DA INDÚSTRIA DO AÇÚCAR E DO ÁLCOOL NO ESTADO DE ALAGOAS - SINDAÇUCAR. Boletim da safra 2011/2012, n.26. 2011. Disponível em: <http://www.sindacucaral.com.br>. Acesso em: 10 nov. 2012.

SINCLAIR, T.R.; GILBERT, R.A., PERDOMO, R.E.; SHINE JUNIOR, J.M.; POWELL, G.; MONTES, G. Sugarcane leaf area development under field conditions in Florida, USA. Field Crops Research, v.88, p.171-178, 2004. http://dx.doi.org/10.1016/j. fcr.2003.12.005

TEODORO, I.; SOUZA, J. L.; BARBOSA, G.V.; MOURA FILHO, G.; DANTAS NETO, J.; ABREU, M.L. Crescimento e produtividade da cana-de-açúcar em cultivo de sequeiro nos Tabuleiros Costeiros de Alagoas. Revista da STAB, v.27, p.31-34, 2009.

THORNTHWAITE, C.W.; MATHER, J.R. Instructions and tables for computing potencial evapotranspiration and the water balance. Ceterton: Drexel Institute of Technology - Laboratory of Climatology, 1957. 311p. (Publications in Climatology, v.X, n.3). 